

\title{
INTRODUÇÃO AOS ESTUDOS DA LINGUAGEM: UMA REFLEXÃÓ SOBRE A PRÁTICA DA MONITORIA ACADÊMICA
}

Valle, Juliana Prudente Santana do ${ }^{1 *}$; Ribeiro, Erislane Rodrigues ${ }^{2}$

1 Graduanda do curso de Letras Português da Unidade Acadêmica Especial de Letras e Linguística (UAELL), da Universidade Federal de Goiás - Regional Catalão

2 Professora Dr. ${ }^{a}$ da Unidade Acadêmica Especial de Letras e Linguística (UAELL), da Universidade Federal de Goiás - Regional Catalão

*email: psvjulina $1 @ g m a i l . c o m$

\section{RESUMO}

Este artigo é o resultado de uma experiência desenvolvida no primeiro semestre de 2014, referente a atividades de monitoria acadêmica exercidas na disciplina Introdução aos Estudos da Linguagem do curso de Letras Português e Letras Português e Inglês. Os objetivos a serem alcançados com as atividades executadas no decorrer da monitoria eram vários, dentre eles, a assistência ao discente nas dificuldades encontradas por ele em relação à leitura e à compreensão dos textos indicados na bibliografia da disciplina; o apoio ao aluno, com a finalidade de auxiliá-lo na compreensão de textos acadêmicos, além do desenvolvimento tanto do monitor quanto do aluno no que diz respeito a sua competência 
textual e ao seu conhecimento teórico dos temas fundamentais do campo dos estudos linguísticos. Com base nos resultados obtidos, pode-se perceber que os alunos se mostraram motivados a participar dos atendimentos marcados pela monitora, em especial em períodos mais próximos das atividades avaliativas. Concluímos, também, a partir da experiência com a monitoria, que se faz necessário uma educação mais comprometida com o desenvolvimento das competências textuais, já que pudemos verificar a dificuldade de muitos alunos com a escrita e a leitura de textos. Vale ressaltar que as atividades extraclasse, em nossa avaliação, proporcionaram aos alunos atendidos conquistas importantes, colaborando com a continuidade e aprofundamento de seus estudos na Universidade. É importante destacar que essa atividade na monitoria funciona como um incentivo valioso para o monitor, na obtenção de experiência docente, fortalecendo e incentivando a vocação acadêmica.

Palavras-chave: Competências Textuais; Experiência Docente; Monitoria Acadêmica.

Revisado pela Orientadora Erislane Rodrigues Ribeiro, contato: erislane@bol.com.br

Valle, Juliana Prudente Santana do; Ribeiro, Erislane Rodrigues; "INTRODUÇ̃̃O AOS ESTUDOS DA LINGUAGEM: UMA REFLEXÃo SOBRE A PRÁTICA DA MONITORIA ACADÊMICA", p. 459-473. In: Seminário de Pesquisa, Pós-Graduação e Inovação da Regional Catalão (2. : 2014 : Goiás) Coletânea Interdisciplinar em Pesquisa, Pós-Graduação e Inovação Volume 2: Humanidades e Letras. Anais [livro eletrônico] / organizado por Adriana Freitas Neves, Idelvone Mendes Ferreira, Maria Helena de Paula, Petrus Henrique Ribeiro dos Anjos. São Paulo: Blucher, 2015.

ISBN: 978-85-8039-111-4, DOI 10.5151/9788580391114-V2_Cap26 


\section{INTRODUC̣ÃO}

Sabe-se que parte dos alunos, ao ingressarem nos cursos de licenciatura das instituições de ensino de nível superior do país, depois de onze anos ou mais na escola, apresentam sérias dificuldades no que tange às atividades de leitura, e interpretação de textos, especialmente os teóricos. Além de demonstrarem sérias dificuldades em elaborações escritas. Dessa maneira, é de suma importância, para que esse aluno tenha sucesso em seus estudos, alcance seus objetivos e até mesmo possa cumprir, num futuro próximo, a sua função de formador, um auxílio para o desenvolvimento de suas competências textuais, as quais, muitas vezes, foram apenas referência ao longo de seus estudos escolares.

Desse modo, mediante os conteúdos ensinados na disciplina Introdução aos Estudos da Linguagem ministrada aos alunos do primeiro período pelos Cursos de Letras da Unidade Acadêmica Especial (UAELL), Regional Catalão/ UFG, os quais se fazem essenciais para dar início à compreensão do desenvolvimento dos estudos linguísticos e o entendimento da linguagem utilizada pelos autores dos textos a serem estudados, vê-se necessário um auxílio para aqueles que apresentam dificuldades em tratar dos gêneros acadêmicos e da teoria neles desenvolvida.

Posto isso, esse artigo visar defender a importância da monitoria, na qualidade de auxílio ao discente no processo ensino-aprendizagem, o qual contribui, em primeira instância, para um melhor aproveitamento do curso, em razão de uma inclusão mais efetiva do aluno nas atividades cotidianas e, em segunda instância, para a sua permanência na universidade, além do que representa um importante instrumento de aquisição e incentivo de hábitos tanto de estudo quanto de pesquisa para o desenvolvimento da formação acadêmica do discente monitor.

Por isso, o exercício da monitoria desenvolvido durante o primeiro semestre de 2014 teve por objetivo, dentre outros, o apoio a esses alunos no que se refere à apreensão dos conceitos e teorias relativos aos estudos linguísticos propostos no plano de curso da referida disciplina, além de auxiliá-los na compreensão dos gêneros acadêmicos nos quais essas noções estão inseridas. Diante da dificuldade de alguns alunos na compreensão de certas noções, o apoio do monitor junto ao professor contribui para melhor entendimento do aluno atendido na monitoria, já que muitos ingressam na Universidade apresentando um déficit n o que concerne à compreensão de textos de maneira geral, o que acaba tornandose um impedimento para a leitura de textos teóricos e, consequentemente, a elaboração de gêneros textuais diversos, como resumos, fichamentos, resenhas e até mesmo a elaboração de respostas de questões avaliativas da disciplina. 
Neste caso, parece, realmente, ser fundamental que os professores de língua portuguesa dos níveis fundamental e médio levem em conta, nas atividades de ensino, a diversidade de gêneros textuais para habilitar o aluno por meio de atividades de leitura, escrita, fala e compreensão, evitando maiores dificuldades quando esse se depara com os gêneros acadêmicos e uma linguagem complexa própria da esfera de atividade acadêmica.

Ensinar gêneros na escola permite melhorar o desempenho dos alunos, principalmente, no que diz respeito à produção e compreensão de textos. $\mathrm{O}$ ensino deve ser ministrado, nesse sentido, com o objetivo de formar leitores e escritores críticos, que saibam se relacionar dentro da esfera em que se encontram e procurar ficar atualizados diante das grandes mudanças que vem ocorrendo com os gêneros, pois, conforme destaca o próprio Bakhtin (2000), à medida que cada esfera se desenvolve e fica mais complexa, os gêneros discursivos vão se ampliando e diferenciando-se, ou seja, novos gêneros surgem, enquanto outros desaparecem, por isso, o aluno deve estar atualizado e ter uma participação efetiva com o que ocorre na sociedade.

Neste sentido, o texto deve servir como a principal unidade de trabalho do professor de língua portuguesa e não como um suporte para as práticas de teorização gramática e de reconhecimento das escolas literárias, por exemplo, como vemos acontecer em boa parte das escolas. Dessa forma, o mais relevante é utilizar os textos dentro das salas de aula como objeto para práticas de interpretação, leitura e produção de textos. Além do que os conteúdos de leitura e produção de textos devem ser selecionados levando em conta sua relevância social e sua contribuição para o desenvolvimento intelectual do aluno, ou seja, as aulas de língua portuguesa devem, conforme os orientam os PCNEMs,

servir para o exercício da fala/escrita na vida social, para que o aluno possa aprender a confrontar, defender, explicar suas idéias de forma organizada, nas diferentes esferas da atividade pública, além de saber compreender e refletir sobre as diversas atualizações que ocorrem na linguagem (BRASIL, 1999, p. 143).

O ensino com gêneros possibilita que o aluno adquira parâmetros para compreender ou produzir textos, uma vez que a eficiência para escrever está relacionada à própria capacidade de olhar do escritor para seu texto produzido, sendo capaz de analisar se está impreciso, desconexo, vago ou mesmo incompleto. Além de permitir que o professor possa intervir de modo mais efetivo no processo de compreensão e produção de seus alunos.

Em referência, ainda, à produção de sentidos, defendidas pelos PCNs, 
Koch (2014) se atem a mostrar que o trabalho de uma análise epilinguística, entendida como as reflexões realizadas a partir do próprio texto com o objetivo de explorar as possibilidades de realizá-lo, é essencial, pois possibilita uma discussão sobre os diversos sentidos aludidos aos textos, os recursos discursivos que podem ou não ser considerados, os quais proporcionam a elaboração de recursos linguísticos que serão usados nas produções textuais.

Dentre os temas, conceitos e noções, abordados pela disciplina, e que foram trabalhados junto aos alunos que procuraram o auxílio da monitoria podem ser mencionados: as concepções de linguagem; a perspectiva descritiva da Linguística em oposição à abordagem prescritiva da Gramática Normativa; as dicotomias saussurianas, as variedades linguísticas, as funções da linguagem, dentre outros. Tais temas foram estudados por meio da leitura e da realização de fichamentos e resumos de textos como os de Petter (2002), Fiorin (2013), Pietroforte (2002), etc. Foram realizadas, ainda, ao longo do semestre, sessões com a professora orientadora da monitoria com a finalidade de dirimir dúvidas relacionadas aos conceitos, bem como com o propósito de planejar as atividades da monitoria.

O exercício da monitoria na graduação é, com efeito, importante também para o monitor, já que, além da oportunidade de aprofundar seus conhecimentos, por meio do contato direto com o professor, tem a possibilidade de experimentar a vida acadêmica, não apenas como aluno, mas também como formador. Ademais, os alunos que necessitam desse apoio e o buscam têm a chance de ampliar suas capacidades linguísticas, visto que esse desenvolvimento os auxiliará, também, na permanência no curso, já que os textos teóricos passarão a fazer parte de suas vidas acadêmicas.

\section{MATERIAL E MÉTODO}

Ao longo de todo o semestre letivo, foram feitas, pela monitora, pesquisas, leituras e resumos dos textos referentes à disciplina Introdução aos Estudos da Linguagem, como também estudos paralelos sobre o desenvolvimento das competências textuais. Além disso, foram realizadas atividades de correção de exercícios propostos pelo professor em sala de aula.

Com relação ao planejamento e à preparação, com o fim de contribuir para o desenvolvimento das competências comunicativas dos alunos, tiveram por objetivo dar condições à monitora de preparar-se teoricamente para, em seguida, elaborar e promover atividades práticas que seriam executadas pelos alunos. Deste modo, foram realizados estudos sobre os gêneros acadêmicos 
mais exigidos nos primeiros períodos dos cursos, tais como fichamento, resumo e resenha descritiva. Foram lidos textos como os de Andrade (2006), Jacobini (2006), Leite (2009), Machado (2004) e Savioli; Fiorin (1993), os quais serviram de base para a preparação de diversas atividades: exercícios de retextualização, produção de fichamentos com ou sem transcrição literal, a elaboração de textos parafrásticos, além da escrita de resumos e resenhas descritivas.

Em Leite (2009), a autora destaca as dificuldades apresentadas pelos estudantes no que tange à compreensão de certos gêneros do discurso, além de enfatizar a necessidade de se trabalhar com os textos acadêmicos a partir da perspectiva dos gêneros:

\begin{abstract}
Compreender o resumo como gênero permitirá ao leitor/escritor posicionar-se adequadamente diante da tarefa de resumir porque os resumos devem ter forma e conteúdo que se adaptem perfeitamente aos fins aos quais se prestam. Saber que o texto-fonte (o texto a ser resumido) é um exemplar de um determinado gênero discursivo permitirá ao leitor/escritor fazer uma leitura compreensiva e eficaz $\mathrm{e}$, consequentemente, produzir um resumo fiel às ideias do texto lido. Desse modo, evidenciamos que estão diretamente envolvidas no processo de resumir as habilidades de leitura e de escrita (LEITE, 2009 , p. 8 , grifos da autora).
\end{abstract}

A clareza dessas concepções, pelo monitor, reforça o embasamento teórico necessário para auxiliar os alunos atendidos pela monitoria. Percebese, também, que se faz essencial, durante esse exercício, pesquisas dos diversos gêneros textuais, uma vez que, reforçam suas próprias competências de leitura e escrita. Segundo essa mesma autora, "O estudo, porém, é o único meio de solucionar todos os problemas relacionados à leitura e à produção de resumos" (LEITE, 2009, p. 62) e também dos outros gêneros do discurso.

Desse modo, no que diz respeito ao embasamento teórico para os atendimentos prestados aos alunos com relação a suas dificuldades em relação aos temas, noções e conceitos abordados na disciplina, houve uma preparação da monitora através da realização de leituras e, em especial, da produção de fichamentos e resumos de textos indicados pela professora à turma ou à monitora como leitura complementar.

Dentre os resumos realizados, pode ser citado, a título de ilustração, um que foi produzido a partir da seção "Uma breve história do estudo da linguagem”, contida no capítulo Linguagem, Língua e Linguística de Petter 
(2002), do livro Introdução à Linguística, organizado por Fiorin (2002). Esse mesmo resumo foi redigido pelos alunos em sala de aula, corrigido pelo monitor e revisado pela professora da disciplina. Nesse texto, segundo Petter (2002, p. 12), "O interesse pela linguagem é muito antigo [...]. Remontam ao século VI a.C os primeiros estudos [...]". As razões que incitaram esses estudos, inicialmente, foram, segundo a autora, para que textos sagrados dos hindus não sofressem alterações no percurso da história. A autora faz um relato do modo como diversos povos e estudiosos abordaram a linguagem. Ela cita os gregos Platão e Aristóteles e o latino Varrão, com seu esforço em definir gramática como ciência e arte. $\mathrm{Na}$ Idade Média viam a estrutura gramatical como una e universal. Em outro momento da história, sobressaiu o método histórico comparativo. Esse método, segundo ela, foi

instrumento importante para o florescimento das gramáticas comparadas e da Lingüistica Histórica [...] O estudo comparado das línguas vai evidenciar o fato de que as línguas se transformam com o tempo, independente da vontade dos homens, seguindo uma necessidade própria da língua e manifestando-se de forma regular (PETTER, 2002, p. 12, grifo da autora).

Dando continuidade ao histórico sobre os estudos da linguagem, a autora chega ao século XX e aos estudos de Saussure, com a publicação do Curso de Linguística geral, o que, segundo ela, dá um caráter científico à abordagem da linguagem. Conforme a linguista, a partir desse momento "O trabalho científico consiste em observar e descrever os fatos a partir de determinados pressupostos teóricos formulados pela Lingüística" (PETTER, 2002, p. 13). Assim o linguista, por meio de um quadro teórico específico, terá a orientação para aproximar-se dos fatos da linguagem, podendo observar diferentes possibilidades de descrição e explicação.

Quanto à elaboração desse resumo pelos discentes, pudemos constatar a dificuldade de alguns alunos, no que diz respeito à estruturação do referido gênero, como sintetizar as informações demostrando a compreensão delas e da própria teoria abordada, outros se limitaram em fazer transcrições da seção, um aluno apresentou uma produção textual indiferente ao conteúdo teórico. Além dessas observações, foram evidenciados desvios da normapadrão da Língua Portuguesa relativos à concordância verbal e nominal, à acentuação, à pontuação e à ortografia. Problemas que favorecem a falta de coesão e coerência textual e colaboram para a não compreensão da mensagem transmitida. Desse modo, torna-se evidente que tais fatores podem 
interferir no processo de leitura e escrita dos alunos e, consequentemente, no entendimento do futuro leitor do resumo elaborado.

Outro texto amplamente trabalhado foi o de Petter (2002), para quem “[...] a linguagem é relativamente autônoma; como expressão de emoções, ideias, propósitos, no entanto, ela é orientada pela visão de mundo, pelas injunções da realidade social, histórica e cultural do falante" (PETTER, 2002, p. 11). Com base neste texto, estudou-se a oposição que se pode estabelecer entre os pontos de vista descritivo e normativo adotados pela Linguística e pela Gramática normativa, respectivamente. A partir da leitura de um outro autor, Pietroforte (2002), teve-se acesso aos estudos saussurianos, os quais concebem a Língua como objeto de estudo da Linguística, propondo que a realização de seu estudo se dê por meio daquilo que denominou dicotomias. Conforme destaca Pietroforte (2002, p. 77), “embora não haja menção ao termo dicotomias no texto do Curso, é assim que se costuma chamar os quatro pares de conceito, que fazem uma síntese das propostas de Saussure para a criação de um novo objeto teórico para a Linguística.” Outro tema abordado por este autor diz respeito à noção de norma desenvolvida por Coseriu, que define a língua como um “[...] sistema articulado com suas normas, ou seja, com suas variantes linguísticas” (PIETROFORTE, 2002, p. 92).

Além dos textos constantes da bibliografia da disciplina, também foram feitas pesquisas em outras fontes para uma maior compreensão dos conteúdos compreendidos na disciplina, dentre elas, o livro "Para compreender Saussure" de Carvalho (2000), o qual se refere à linguística como objeto científico da linguagem, descrevendo suas fases antes de ser considerada como tal, sendo elas: filosófica, referindo-se à origem da linguagem e seus precursores, os gregos, ao ponto de se afirmar que as raízes do pensamento linguístico ocidental estão, profundamente, arraigadas na Grécia Antiga; filológica, surgida na Alexandria em torno do século II a.C, definida como estudo da elucidação de textos, além de ser voltada à Morfologia, à Sintaxe e à Fonética; e Histórico-Comparativa, iniciada com a descoberta do Sânscrito por volta de 1786 e 1816, cuja finalidade era identificar as relações de parentesco entre o latim, o grego, as línguas germânicas, eslavas e célticas com a antiga língua da Índia. Destaca-se, também, nessa fase, Franz Bopp (1791-1867), considerado o fundador da Linguística Histórica. Carvalho (2000), nessa obra, reflete sobre a teoria Linguística de uma forma geral, ressaltando a comparação entre as abordagens de Coseriu e Saussure quanto à tricotomia língua/norma/fala e a dicotomia língua/fala, respectivamente, abordando detalhadamente as dicotomias saussurianas: 
língua X fala, diacronia X sincronia, significante $\mathrm{X}$ significado, paradigma $\mathrm{X}$ sintagma, como as variantes linguísticas estudadas a partir da noção de norma proposta por Coseriu. Entre elas, as diatópicas, as quais se referem às variantes regionais e as diastráticas, relativas às variantes sociais. Segundo Carvalho (2000), apesar da inserção do conceito de norma desenvolvido por Coseriu aos estudos linguísticos

é reconhecidamente incontestável o valor da famosa distinção saussuriana entre langue e parole para a linguística contemporânea. Sua primeira dicotomia, investida de verdadeiro valor epistemológico é e será sempre um fundamento da ciência linguística. (CARVALHO, 2000, p. 16).

Como foi adiantado, as resoluções das atividades oferecidas em sala, corrigidas pela monitora serviram para melhor aprofundamento do conteúdo e, também, favoreceram uma maior interação do professor com os alunos, para um futuro atendimento deles. A título de exemplo, podemos citar atividades relacionadas às abordagens prescritiva e normativa, sobre a dicotomia língua e fala, e a respeito das funções da linguagem. Para a realização dessa correção, aliás, foi necessário o estudo do texto "A linguagem humana: do mito à ciência", de Fiorin (2013). Segundo ele: "A linguagem humana é a capacidade específica da espécie humana de se comunicar por meio de signos" (FIORIN, 2013, p. 13), respondendo a uma necessidade própria do ser humano de comunicar-se. Segundo o autor, ela produz sentidos vários e se manifesta de diferentes maneiras, assumindo, portanto, funções diversas.

Para se fazer entender, o autor faz uma série de análises, demonstrando para que serve a linguagem, isto é, suas variadas funções, tais como interpretar a realidade, promover a interação, possibilitar a busca de informações, promover o convencimento do interlocutor por meio da argumentação, chegando à seguinte conclusão:

Depois de analisar todas as funções da linguagem, compreendese por que ela é onipresente. Sem ela, não se pode estruturar o mundo do trabalho, pois é ela que permite a cooperação entre os homens e a troca de informações e de experiências. Sem ela o homem não pode conhecer-se nem conhecer o mundo. Sem ela não se exerce a cidadania, porque os eleitores não podem conhecer o mundo. Sem ela não se pode aprender, sem ela não se podem expressar os sentimentos, sem ela não se podem imaginar 
outras realidades, sem ela não se constroem as utopias e os sonhos. Sem ela... Sem ela... Sem ela... (FIORIN, 2013, p. 32)

Dessa forma, o estudo de textos teóricos e a prática de análises sobre os conteúdos foram práticas frequentes e imprescindíveis para o êxito do exercício da monitoria da disciplina Introdução aos Estudos da Linguagem, além do que enriqueceram os conhecimentos da monitora, e, por conseguinte, possibilitaram o auxílio ao aluno atendido, já que, por meio desses estudos, pôde-se perceber a complexidade dos conteúdos abordados na referida disciplina, os quais são essenciais para o entendimento de noções relativas à linguagem.

Para a realização desse trabalho, os alunos atendidos pela monitoria fizeram leituras e resolveram exercícios elaborados a partir dos textos específicos da disciplina que estão no plano de curso e, juntamente com a monitora, puderam sanar algumas dúvidas, bem como resolveram os exercícios oferecidos em sala de aula como modo de verificação da apreensão das discussões.

Além disso, a monitora auxiliou a professora no processo de verificação de aprendizagem, por meio da correção de resumos e outras atividades produzidas pelos alunos e, ainda, acompanhou e orientou os discentes em eventos acadêmicos dentro da Regional Catalão, como o lançamento de livros de professores da própria Universidade.

Durante os encontros com a orientadora, houve a possibilidade de realizar reflexões e, também, discussões sobre as dificuldades encontradas pelos alunos matriculados na disciplina bem como pela própria monitora, no que tange à compreensão do conteúdo abordado e suas implicações para o processo ensino-aprendizagem.

\section{RESULTADOS E DISCUSSÕES}

Durante o exercício da monitoria, como forma de preparação da monitora, foram lidos os textos trabalhados pelo professor em sala de aula e, também extracurriculares, além da resolução das atividades propostas por ele. Encontros entre o professor e a monitora foram realizados semanalmente, assim, além da interação proporcionada por tal acontecimento, houve a oportunidade de discutir o conteúdo e solucionar dúvidas, visto que ficou clara a necessidade do empenho da monitora e o engajamento do professor com o trabalho, uma vez que esse contato favorece maior segurança e aperfeiçoamento no êxito 
da monitoria. A partir dessa interação, a monitora teve a oportunidade de aprimorar seus conhecimentos e se preparar para o exercício da monitoria, sem contar que esse trabalho é uma forma de despertar o desejo em relação à docência como uma futura prática profissional, já que essa está vinculada ao desenvolvimento do ensino e à prática da pesquisa, fundamental à prática do professor. Com isso, estamos de acordo com autores como Ilari (1992), que defende a importância da linguística para o futuro professor de português. No entanto, fazemos a ressalva de que sejam realizadas atividades de pesquisa que se vinculem mais diretamente aos fazeres cotidianos dos professores de Língua, pois é preciso que se faça da pesquisa o modo, por excelência, de se pensar e direcionar a nossa prática escolar.

$\mathrm{O}$ atendimento da monitoria, realizado em horários diversos, distribuídos durante a semana, trouxe conquistas para alguns alunos, pois além de serem aprovados na disciplina, sentiram-se incentivados a permanecer no curso, possibilitando-lhes a oportunidade de aprofundar em seus estudos. As correções das atividades realizadas pela monitora, sob orientação da professora, pode despertar nos alunos, da referida disciplina, a necessidade de um maior comprometimento com a leitura e compreensão dos gêneros acadêmicos e, consequentemente, de suas produções textuais.

No que diz respeito à adequação de horários para serem realizados os encontros de atendimento dos alunos pela monitora, algumas dificuldades foram encontradas, pois os atendidos trabalhavam o dia todo, uma das alunas trabalhava e residia em outro município e justamente essa aluna não conseguiu alcançar seu objetivo, que era ser aprovada na disciplina. Por isso, fizeramse necessários reajustes nesses horários ao longo do semestre, até mesmo aproveitamento de horário sem aula da monitora para prover esse atendimento, remanejando, assim, a carga horária.

Pode-se perceber que alguns graduandos mostraram-se interessados devido as suas participações nos atendimentos da monitoria e, assim, puderam ser auxiliados na compreensão da disciplina. Discentes, os quais demonstravam acentuada dificuldade em leitura, interpretação, no que se refere aos textos acadêmicos, conseguiram avanços em seus estudos. Dessa maneira, essas atividades realizadas fora da sala de aula trouxeram conquistas para eles, até mesmo contribuíram para o sucesso em outras disciplinas do próprio curso. Verifica-se, contudo, que o trabalho da monitoria ainda não é considerado importante para muitos graduandos, seja por falta de conhecimento ou mesmo desvalorização por parte dos próprios alunos, causando uma certa desilusão à monitora, visto que esse se prepara com muito empenho para realização desse trabalho. É importante destacar que a monitora tem a oportunidade 
de desenvolver habilidades relativas à docência, de forma enriquecedora, propiciando experiência acadêmica, também podendo aplicar-se ao conhecimento da disciplina específica, dado que são necessárias pesquisas de outras fontes, além das recomendadas pelo professor da disciplina para auxiliar no processo ensino-aprendizagem. Afora, o contato pessoal tanto com o corpo docente quanto discente, o qual incentiva e fortalece, dessa maneira, a vocação acadêmica.

\section{CONCLUSÃO}

Percebe-se, a partir do trabalho realizado pela monitoria e dos objetivos alcançados, o quanto importante é esse exercício realizado no ambiente acadêmico. Uma vez que o monitor, além de auxiliar seus colegas em suas dificuldades de apreensão dos conteúdos discutidos na disciplina, no caso Introdução aos Estudos da Linguagem, tem a oportunidade de vivenciar a experiência acadêmica, seja experimentando as alegrias ou mesmo os dissabores da carreira de formador, já nos períodos iniciais de sua graduação.

Por meio do trabalho com a monitoria, torna-se evidente o quão essencial é uma educação que tenha compromisso com o exercício da cidadania, a qual deve criar condições para que o aluno possa desenvolver sua competência textual, dando-lhe garantias de uma maior possibilidade de inserção nas práticas comunicativas. Um dos aspectos da competência textual fundamental em nossa sociedade é a capacidade do sujeito de compreender a língua de modo variado, para produzir diferentes efeitos de sentido e adequar seu texto a diferentes situações de interlocução seja na fala, seja na escrita. Por isso, fica claro a importância de serem contemplada nas atividades de ensino propostas pelos professores de língua portuguesa dos diversos níveis de ensino, a multiplicidade de gêneros textuais, posto que textos pertencentes a gêneros diversificados se organizam de forma diferente, com estruturas e características particulares. Assim, fica evidente a importância de tais formadores buscarem estratégias de ensino voltadas, também, para esse desenvolvimento textual, já que não há uma interpretação única a ser aperfeiçoada nas salas de aula.

Tanto a compreensão oral e escrita, como a produção oral e escrita de textos relacionados a gêneros diversos, depreendem o desenvolvimento de várias capacidades que precisam ser destacadas nas situações de ensino. É a partir do desenvolvimento dessas competências textuais dos alunos que a escola, em todos os níveis de ensino, deve planejar suas atividades curriculares no que concerne ao ensino-aprendizagem da leitura e da escrita. Desse modo, os 
discentes poderão adentrar na Universidade, amparados por essa competência, aptos para alcançarem seus objetivos e se tornarem formadores ou mesmo continuarem se especializando. Além do mais, serão respaldados pelo trabalho realizado pela monitoria acadêmica, a qual contribui para o desenvolvimento, a permanência e a conclusão do tão desejado curso universitário. 


\section{Title: Introduction to language studies: a reflection about the academic tutoring}

\section{Abstract}

This article is the result of an experience developed in the first semester of 2014, refering to activities of academic monitoring carried out in the discipline of Introduction to the Language Studies in the Language degree course of Portuguese and English. The objectives to be achieved with the activities performed during the monitoring were several, amongst them, the assistance to the student with issues in relation to reading comprehension in the texts indicated by the bibliography in the discipline; the support to the student with the intention of assisting during the comprehension of academic texts, beyond the development of the monitor or the student on its textual proficiency and its theoretical knowledge of the fundamental themes in the area of Linguistics studies. Basing in the obtained results, it's possible to realize that the students show themselves motivated in participating in the monitoring attendance, in special in periods close to the evaluative activities. We conclude, also, based in the experience of monitoring, which is necessary an education more committed with the development in the textual competences, as we verified the struggle in many students with the reading and writing of texts. To emphasize that the extra classes activities in our evaluation provided our students important achievements, collaborating with the continuing and deepening their studies in the University. It's important to emphasize that this activity in the monitoring works as a valuable incentive to the monitor, in obtainment of experience as a teacher, contributing and motivating the academic carrer.

Keywords: Textual competences; Teaching experience; Academic Monitoring. 


\section{REFERÊNCIAS}

ANDRADE, Maria Lúcia C. V. O. Resenha. São Paulo: Paulistana, 2006.

BAKHTIN, M. Os gêneros do discurso. In:

. Estética da criaç̃áo verbal. São Paulo: Martins Fontes, 2000. BRASIL, Ministério da Educação, Secretaria de Educação Média e Tecnológica. Parâmetros curriculares nacionais: ensino médio. Braślia: Ministério da Educação, 1999. p. 137-144.

CARVALHO, Castelar de. Para compreender Saussure: fundamentos e visão crítica. Petrópolis: Vozes, 2000. Disponivel em: <http://copyfight.me/Acervo/livros/para\%20compreender\%20saussure\%20-\%20castelar\%20de\%20 carvalho.pdts. Acesso em: 26 set. 2014.

FIORIN, José Luiz. A linguagem do mito à ciência. In: FIORIN, José Luiz (Org.). Linguística: que é isso? São Paulo: Contexto, 2013. p. 13-32.

JACOBINI, Maria Letícia de Paiva. Metodologia do trabalho acadêmico. 3. ed. Campinas: Alínea, 2006.

KOCH, Ingedore Villaça. As tramas do texto. 2. ed. São Paulo: Contexto, 2014.

LEITE, Marli Quadros. Resumo. São Paulo: Paulistana, 2009.

MACHADO, Anna Rachel. Resumo. São Paulo: Parábola Editorial, 2004.

PETTER, Margarida. Linguagem, língua, linguística. In: FIORIN, José Luiz (Org.). Introducção à Linguística. São Paulo: Contexto, 2002. p. 11-24.

PIETROFORTE, Antônio Vicente. A língua como objeto da Linguística. In: FIORIN, José Luiz (Org.). Introdução à Linguística. São Paulo: Contexto, 2002. p. 75-93.

SAVIOLL, Francisco Platão; FIORIN, José Luiz. Para entender o texto: leitura e redação. São Paulo: Ática, 1993. $431 \mathrm{p}$. 